\title{
A GLOBALIZAÇÃO, O DECLÍNIO DA SOBERANIA DO ESTADO E A CRISE ECONÔMICA DE 2007/2008: a necessidade de criação de um sistema de governança econômica global
}

\author{
Argemiro Luis Brum' \\ Gilmar Antonio Bedin² \\ Márcia Naiar Cerdote Pedroso 3
}

\section{Resumo}

0 presente artigo esclarece que há uma grande vinculação entre 0 fenômeno da globalização, 0 declínio da soberania dos Estados e a conformação da crise econômica de 2007/2008. Neste sentido, o texto destaca que a fragilização da soberania dos Estados fortaleceu os fluxos econômicos globais. Nesse contexto, o artigo chama a atenção para a necessidade de criação de um sistema de governança econômica global e, em consequência, destaca a importância da fixação de regras e de procedimentos para a regulação do mercado e para tornar mais efetivos os controles dos fluxos

${ }^{1}$ Doutor em Economia Internacional pela EHESS de Paris (França) e professor permanente dos cursos de Mestrado em Desenvolvimento e de Direitos Humanos da Universidade Regional do Noroeste do Estado do Rio Grande do Sul - Unijuí. É autor, entre outras obras, de “Economia Internacional”. argelbrum@unijui.edu.br

${ }^{2}$ Doutor em Direito do Estado pela UFSC e professor permanente do curso de Mestrado em Direitos Humanos da Universidade Regional do Noroeste do Estado do Rio Grande do Sul - Unijuí - e professor colaborador do curso de Mestrado em Direito da Universidade Regional Integrada do Alto Uruguai e Missões - URI. É autor, entre outras obras, de “A Idade Média e o Nascimento do Estado Moderno”. gilmarb@unijui.edu.br

${ }^{3}$ Economista e especialista em Pensamento Político Brasileiro pela UFSM. Mestre em Desenvolvimento da Unijuí/RS. marciacerdote@brturbo.com.br 
econômicos globais. Na parte final, o texto defende que este sistema de governança econômica global se alicerce numa estrutura multilateral e represente os interesses dos Estados, das populações e dos mercados.

Palavras-chave: Estado. Soberania. Globalização. Crise econômica. Governança global.

\title{
GLOBALIZATION, STATE SOVEREIGNTY DECREASE AND 2007/2008 ECONOMIC CRISIS: the need to create a global economic governance system
}

\begin{abstract}
This paper shows that there is strong bonding between the phenomenon of globalization, state sovereignty decrease and the conformation of the $2007 / 2008$ economic crisis of. In this sense this paper highlights that the weakening of state sovereignty strengthened global economic flows. Hence this paper pays attention to the need to create a global economic governance system e therefore stresses the importance of fixing rules and procedures for market regulation and the improvement of global economic flow control. Finally paper maintains that this global economic governance system should base on a multilateral feature and represent the interests of states, peoples and markets.
\end{abstract}

Keywords: State. Sovereignty. Globalization. Economic crisis. Global governance. 


\section{GLOBALIZAÇÃO: uma grande mudança histórica}

A configuração do mundo como um sistema global é um dos mais significativos acontecimentos políticos, econômicos e sociais das últimas três ou quatro décadas. Por isso, a sua consolidação é um marco simbólico-referencial importante da entrada da humanidade num novo século e também numa nova e complexa fase da sua trajetória: o momento da vida em comum no planeta.

Esta nova fase é marcada por um processo de grandes transformações, em que há a unificação do planeta e a ampliação do "sistema-mundo" para todos os lugares e para todos os indivíduos, embora com intensidade e graus diversos. A Terra torna-se, nesse novo contexto, um "só e único 'mundo' e assiste-se a uma refundição da 'totalidade-terra”' (Santos, 1997, p. 48). A vida torna-se interdependente e passa a ser conectada em escala global. Daí a percepção de que todos os acontecimentos estão inter-relacionados e que são relevantes para a humanidade.

O planeta adquire, com isto, um novo status e transforma-se num território de todo o mundo (a única casa para todos). Em consequência, as distâncias encolhem e os acontecimentos de qualquer parte do mundo tornam-se familiares e são acompanhados por parcelas significativas da população mundial. Nesse sentido,

tudo se desterritorializa e reterritorializa. Não somente muda de lugar, desenraiza-se circulando pelo espaço, atravessando montanhas e desertos, mares e oceanos, línguas e religiões, culturas e civilizações (Ianni, 1996, p. 169).

As fronteiras são abolidas ou tornam-se irrelevantes ou inócuas; fragmentam-se e mudam

de figura, parecem, mas não são. Os meios de comunicação, informação, transporte e distribuição, assim como os de produção e consumo, agilizam-se universalmente. As descobertas científicas, transformadas em tecnologias de produção e reprodução material e espiritual, espa- 
lham-se pelo mundo. A mídia impressa e eletrônica, acoplada à indústria cultural, transforma o mundo em paraíso das imagens, vídeo-clipes, supermercados, shopping centers, Disneylândias (Ianni, 1996, p. 170).

Trata-se, portanto, de uma revolução global "na vida corrente, cujas consequências se estão a fazer sentir em todo o mundo, em todos os domínios, do local de trabalho à política” (Giddens, 2000, p. 23). Assim, a globalização "não é apenas uma coisa nova, é também algo de revolucionário" (p. 20). Além disso, "as mudanças que nos afetam não estão confinadas a nenhuma zona do globo, se fazem sentir um pouco em toda a parte” (p. 13).

Este acontecimento transforma a vida nas diversas regiões do planeta, gera novas percepções e abre caminho para novas possibilidades. Com isto, são modificados equilíbrios preexistentes e passam a ser impostas suas determinações. Por isso, é possível afirmar que a globalização possui um alcance planetário e uma conformação abrangente (o que permite o estabelecimento de um novo sentido para a existência humana) e força suficiente para poder determinar os rumos da vida nesse novo século.

Assim, a emergência do fenômeno da globalização significa a conformação de um novo ciclo da História humana: um período cada vez menos nacional e cada vez mais global. Por isso, a globalização do mundo é uma grande mudança histórica e um acontecimento de cunho planetário. As suas principais características são a crescente fragilização das fronteiras e identidades nacionais, a intensificação da integração da vida das diversas regiões da Terra, o grande encurtamento das distâncias e a formação de um único sistema econômico de alcance mundial.

\section{DECLÍNIO DO CONCEITO DE SOBERANIA E REDEFINIÇÃO DO PAPEL DO ESTADO}

Além disso, a globalização caracteriza-se também pelo declínio do conceito de soberania e pela redefinição do papel do Estado. Nesse sentido, é possível perceber que o Estado adquiriu, diante da complexidade 
dos fluxos globais, um novo estatuto (uma entidade política dotada de soberania e autonomia relativas) e passou a desempenhar novas funções: fomentar a liberação dos mercados, criar blocos de integração regional e instituir organizações econômicas internacionais.

A relativização dos conceitos de soberania e a redefinição do papel do Estado é um dos acontecimentos de grandes proporções. De fato, as implicações deste acontecimento são significativas, sendo possível dizer que o denominador comum das profundas rupturas políticas e econômicas produzidas nas últimas décadas é justamente o esvaziamento da soberania do Estado. Assim o Estado,

por um lado, já não pode mais querer regular a sociedade civil nacional por meio de seus instrumentos jurídicos tradicionais, dada a crescente redução de seu poder de intervenção, controle, direção e indução. Por outro, ele é obrigado a compartilhar sua soberania com outras forças que transcendem o nível nacional [Ao promulgar as leis, portanto], os Estados nacionais acabam sendo obrigados a levar em conta o contexto econômico-financeiro internacional, para saber o que podem regular e quais de suas normas serão efetivamente respeitadas (Faria, 1994, p. 11).

A fragilização do conceito de soberania fortaleceu os fluxos transnacionais (que atravessam as fronteiras nacionais e se articulam mundialmente a partir de diversos centros de poder) e submeteu os Estados a uma complexa rede de relações econômicas de alcance global. Esta perda de autonomia do Estado tornou impossível o isolamento político, econômico e social no interior de suas fronteiras territoriais, pois os acontecimentos locais passaram a ser "determinados ou modelados por eventos que ocorrem a muitas milhas de distância” (Giddens, 1991, p. 69).

Desta forma, percebe-se que a soberania do Estado diluiu-se num conjunto de redes de fluxos econômicos, de redes de comunicação, de intercâmbio de experiências culturais e de influências políticas mútuas. 
Em consequência, o poder do Estado passou a ser dividido com outras instituições de caráter não nacionais e nem territoriais e alicerçadas em pressupostos globais.

O poder do Estado, dessa maneira, tem sido reduzido e sua autoridade sobre os fluxos econômicos globais e sobre as atividades que ocorrem sobre seu território tem se enfraquecido. Esta fragilização do Estado contribui para a sensação de que os Estados têm se tornado cada vez "menos efetivos como administradores de seus próprios assuntos" (Matias, 2005, p. 172) e o mundo cada vez mais complexo e economicamente interdependente e mais caótico e turbulento. Esta nova realidade pôde ser verificada claramente na crise econômica de 2007/2008 que se estende por mais de cinco anos.

\section{A CRISE DE 2007/2008}

\subsection{A origem da crise}

Os problemas econômicos que o mundo presencia nos últimos anos não é uma crise conjuntural como as anteriores. Nesse sentido, as crises ocorridas no México em 1994, no Brasil em 1999 e na Argentina em 2001 foram de caráter localizado e com efeitos parciais sobre a economia mundial. A crise econômica de 2007/2008 é bem distinta na medida em que emergiu a partir de uma das maiores economias do planeta e pode ser considerada a primeira crise do sistema econômico global, ${ }^{4}$ a ponto de ser comparada com a grande crise econômica de 1929.

\footnotetext{
${ }^{4}$ Nesse sentido, José Eduardo Faria (2011) chama a atenção que a crise teve como epicentro o colapso financeiro norte-americano, mas foi exponenciada pela interconexão das instituições financeiras em escala global existente na atualidade.
} 
O problema teve início com a queda do valor dos imóveis nos Estados Unidos, resultante da crise do setor habitacional e refletiu-se de forma generalizada pelas diversas partes do mundo. ${ }^{5}$ Para entendermos esta crise, é importante salientar que a economia norte-americana já vinha passando, desde o início de 2000, por um período recessivo. Nesse sentido, ocorreu, primeiramente, o estouro do mercado acionário do segmento de alta tecnologia - "Bolha Pontocom". Este fenômeno deu-se pelo fato de que vários setores ligados às novas tecnologias tiveram um desempenho aquém do esperado. "Em março de 2000, a convenção altista foi revertida. Entre março e dezembro desse ano, o Índice Nasdaq ${ }^{6}$ caiu quase 50\%” (Cagnin, 2009, p. 151). Em segundo lugar, houve a crise de confiança na economia norte-americana (em especial depois de 11 de setembro de 2001), fato que intensificou o movimento de queda dos preços das ações.

Diante deste cenário, o Banco Central Norte-Americano (FED) adotou, junto com outras medidas macroeconômicas expansivas, uma sequência de cortes na taxa de juros básicas (chegando até 1\%) como uma forma de combate à paralisia econômica. Nesse sentido, lembra o economista Paul Krugman (2009, p. 158) que

[...] o FED estava profundamente preocupado com a debilidade do mercado e com a prostração generalizada da economia, que parecia muito semelhante à do Japão na década de 1990 [e que entendia que era fundamental o seu aquecimento].

5 José Eduardo Faria (2011, p. 22) observa ainda que a crise "atingiu todos os mercados - do monetário ao de crédito, das bolsas de valores e de mercadorias às operações com opções de compra, contratos de futuros e swapes. A crise não se circunscreveu apenas a bancos comerciais, a bancos de investimentos, a caixas de depósitos. Ela também envolveu instituições não financeiras, como o caso das seguradoras, de grandes empresas do setor de construção civil e até mesmo de companhias industriais e comerciais...”.

6 Índice norte-americano de ações. 
A política de redução das taxas de juros do FED foi instituída e permitiu um novo ciclo de expansão econômica, a qual foi feita principalmente a partir do crédito residencial, que foi estendido para as famílias de rendas mais baixas e gerou o desenvolvimento de um imenso segmento de hipotecas securitizadas. Até esse momento as operações de securitização de hipotecas residenciais (mortgage backed securities ou MBS) estavam ancoradas apenas em quatro instituições, além dos bancos hipotecários e das instituições de poupança (S\&L): FHA, Ginnie Mae, Fannie Mae e Freddie $\mathrm{Mac}^{7}$ (companhias abertas com apoio governamental).

Dada a expansão do crédito hipotecário, a maior liquidez no mercado secundário de MBS e o baixo patamar das taxas de juros, agentes financeiros, como os grandes bancos comerciais privados, ${ }^{8}$ passaram também a ser securitizadores de hipotecas e buscaram atrair clientes que não se enquadravam nas exigências das GSE. ${ }^{9}$ Esse fato expandiu enormemente $o$ volume de títulos emitidos por hipotecas não tradicionais (hipoteca com baixa garantia). Estas operações fizeram surgir o que Paul

7 Federal Housing Administration (FHA), Government National Mortgage Association (Ginnie Mae), Federal National Mortgage Association (Fannie Mae) e Federal Home Loan Mortgage Corporation (Freddie Mac).

8 Os grandes bancos norte-americanos foram estendendo suas atividades para além dos tradicionais empréstimos bancários, passando a administrar fundos mútuos e a oferecer serviços de gestão de ativos por meio de seus vários departamentos. Buscaram ainda escapar das regras prudenciais, promovendo a securitização dos créditos. Enfim, para enfrentar a concorrência, "os bancos reivindicaram e foram se transformando em supermercados financeiros, desencadeando um processo que culminou na separação das funções entre os bancos comerciais e de investimentos imposta pelo Glass-Steagle Act (1933). Desde os anos 70 os grandes bancos americanos já eram dominantes no mercado internacional de moedas estrangeiras. Mais recentemente, eles desenvolveram um nicho altamente arriscado, mas que se tem mostrado rentável - dadas as suas relações com o empregador de última instância - ao passarem a fornecer seguros financeiros (hedge) como dealers do mercado de derivativos e a abrir linhas de crédito nas emissões de commercial paper e outros títulos de dívida no mercado de capitais” (Cagnin; Cintra, 2007, p. 306).

${ }^{9}$ Grid de Sustentabilidade Empresarial. 
Krugman (2009) denominou de sistema bancário paralelo (instituições desregulamentadas que se equipararam em importância ao sistema bancário tradicional).

A convergência desses fatores permitiu um salto no mercado residencial. Nesse sentido, Gontijo (2008, p.16) explica que "a taxa média de elevação dos preços dos imóveis foi de $6,4 \%$ ao ano no período de 2000 2005 , com o pico sendo atingido em 2005, ano em que os preços das residências sofreram uma elevação na ordem de 14\%”. Esta expansão do mercado imobiliário levou as companhias hipotecárias a passarem a explorar o segmento de subprime. A exploração desse novo segmento foi o estopim da crise econômica que eclodiu em 2007.

\subsection{A Conformação da Crise}

A exploração do segmento subprime foi, de fato, o elemento decisivo? Sem dúvida, foi. É que a conformação deste novo mercado permitiu expansão, de forma acelerada, do mercado imobiliário. Nesse sentido, foi gerado um número impressionante de contratos hipotecários, mas com poucas garantias de efetivo pagamento. É que esses contratos, de acordo com Cláudio Gontijo (2008), são aqueles em que o comprador adquire um imóvel por meio de financiamento, mas sem qualquer valor de entrada e sem comprovação da capacidade de pagamento. Esse fato é o que diferencia estas hipotecas (subprime) daquelas com garantias sólidas e capacidade de pagamento comprovada (prime).

O crescimento do mercado de hipotecas subprime foi, de fato, impressionante. ${ }^{10}$ Vejam o gráfico a seguir:

${ }^{10}$ E revelou que os bancos e instituições passaram a operar "com uma crescente tolerância a risco, buscando retornos cada vez mais elevados. Com isto, multiplicaram-se as operações especulativas e de curto prazo, em detrimento de investimentos produtivos de médio e 
Gráfico 1: Evolução das hipotecas subprime nos EUA (1994-2006)

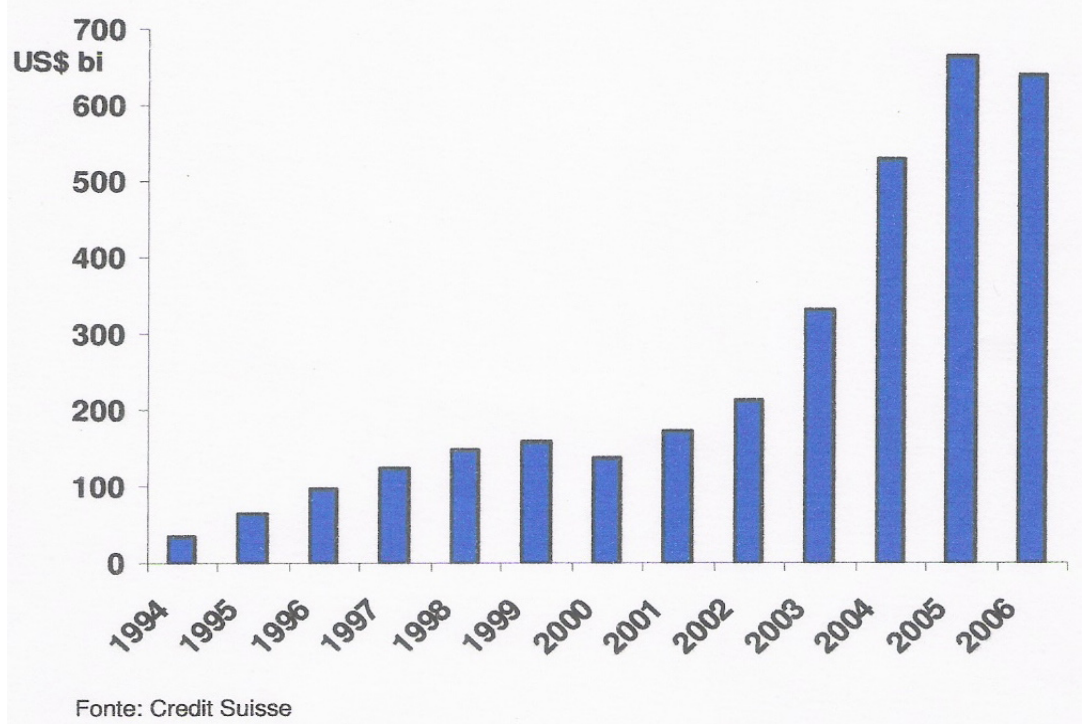

Fonte: Crédit Suisse.

Essa expansão foi fundamental para o aquecimento da economia norte-americana. Além disso, teve uma participação importante nesse cenário o fato de que vários bancos de Wall Street gastaram milhões de dólares com o lançamento de significativas campanhas publicitárias, incentivando os americanos a aumentarem suas dívidas relacionadas às hipotecas. Nesse sentido, chamou a atenção Peter Gowan (2009) que o Citigroup lançou uma campanha de um bilhão de dólares com o lema "viva ricamente", que tinha como objetivo induzir os proprietários de imóveis a fazerem uma segunda hipoteca e ampliarem seu endividamento. O mesmo foi feito por outros bancos. Assim, "as dívidas provenientes de segundas hipotecas subiu para mais de US\$ 1 trilhão” (Gowan, 2009, p. 59).

longo prazos, o que resultou numa riqueza financeira progressivamente desconectada da riqueza real e num regime de acumulação caracterizado pela ausência de uma regulação firme e eficiente" (Faria, 2011, p. 23). 
Desta forma, o mercado de imóveis alcançou um volume impensável e, em consequência, tornou-se insustentável. Este processo começou a se inviabilizar a partir de 2005 e se consolidou como tendência em 2006. O problema foi que os preços dos imóveis começaram a cair, em especial a partir do segundo semestre de 2006, iniciando um processo de implosão do sistema. Nesse viés, lembra Paul Krugman (2009, p.175) que, embora lentas, "as primeiras quedas nos preços das casas já foram suficientes para solapar os alicerces sobre os quais se sustentava o surto de empréstimos subprime".

No início de 2007 este processo de queda do valor dos imóveis continuava a ocorrer e atingiu o seu pico de queda no período que vai da metade daquele ano até a metade de 2008. Nesse período a desvalorização dos imóveis “alcançou 15\%” (Krugman, 2009, p. 175). Esta queda dos preços foi motivada por dois fatores: pelas dificuldades crescentes de pagamento das hipotecas e pela oferta excessiva de imóveis (Gontijo, 2008). A convergência destes dois fatores paralisou o mercado.

Com isso, os imóveis perderam valor e surgiu o problema da execução das hipotecas. Esse problema não era apenas dos proprietários dos imóveis, mas também dos credores que haviam financiado seus empreendimentos. A saída mais evidente para esse impasse era os proprietários negociarem com o credor a redução das prestações, mas, isso não é fácil.

A esse respeito, lembra Paul Krugman (2009, p. 175-176) que, para começar, essa alternativa também custa dinheiro, pois exige pessoal especializado e a destinação de muitas horas de negociação. Além disso,

os empréstimos subprime em geral não eram concedidos por bancos que se mantinham na condição de credores mas, sim, por agentes que rapidamente repassavam os empréstimos para instituições financeiras, as quais, por sua vez, fatiavam e picavam pools de hipotecas em "collateralized debt obligation” (títulos garantidos por dívida), ou CDOs, que 
eram vendidos a investidores. A efetiva gestão dos empréstimos ficava por conta de intermediários (loan servicers), que não dispunham nem de recursos nem, quase sempre, de motivação para promover reestruturação de dívidas. E, ainda por cima, a complexidade da engenharia financeira que sustentava os empréstimos subprime, dispersando a propriedade das hipotecas entre muitos investidores, com diferentes níveis de prioridade no recebimento, erguia obstáculos legais formidáveis a qualquer tipo de renegociação.

Percebe-se, desta forma, que uma reestruturação das dívidas era, na maioria dos casos, inviável (uma vez que envolveria altos custos na execução das hipotecas). Além disso, os títulos lastreados em hipotecas subprime tornaram-se, rapidamente, péssimos investimentos e ninguém estava disposto a negociá-los. Assim, o mercado foi sendo paralisado e mesmo negócios tradicionais tinham dificuldades para alcançar um patamar mínimo de segurança para serem realizados. Esta paralisia alcançou imediatamente as instituições financeiras envolvidas.

Assim, a crise foi espalhando-se e gerando desconfiança em todo o mercado. O resultado foi a retração do crédito e, em consequência, a produção de uma crise de liquidez. Desta forma, a crise imobiliária do mercado subprime atingiu os mercados financeiros e de capitais dos Estados Unidos e dos países da Europa que possuíam bancos ligados à securitização das hipotecas de alto risco.

As perdas foram acumulando-se nas instituições financeiras, particularmente naquelas originadoras de MBSs.

O problema veio à tona em fevereiro de 2007, quando o HSBC divulgou balanço com perdas em operações imobiliárias. Em abril, a New Century Financial, uma empresa especializada no mercado subprime, quebrou, dispensando metade de seus empregados [...] (Contijo, 2008, p. 25). 
Com a queda do valor dos ativos de grandes instituições financeiras norte-americanas e europeias, os bancos centrais dos países envolvidos intervieram e injetaram um volume significativo de recursos. De fato,

a pronta e maciça intervenção do $F E D$, que injetou US\$ 64 bilhões no sistema financeiro em poucos dias, do Banco Central Europeu (BCU), que alocou US\$ 313,1 bilhões, e do Banco do Japão, que, inicialmente, colocou US\$13,5 bilhões, trouxe certa tranqüilidade ao mercado na segunda metade do mês de agosto, arrefecendo o pânico que se instalara [...] (Gontijo, 2008, p. 26).

Isto, contudo, não resolveu o problema. Mesmo com forte intervenção estatal e sucessivos cortes na taxa básica de juros pelo FED (entre outras iniciativas para superar esse abalo), novos momentos críticos surgiram. Este processo culminou com o colapso do Bear Stearns, grande banco de investimento, em março de 2008, e com a quebra do banco Lehman Brothers, em setembro do mesmo ano. Nesse cenário, a intervenção governamental foi decisiva.

Nesse sentido, lembram Rafael Fagundes Cagnin e Marco Antonio Cintra $(2007$, p. 36) que a tensão estabelecida

nos mercados financeiros globais exigiu a intervenção agressiva das autoridades monetárias de maneira a garantir a liquidez do mercado interbancário. Calcula-se que o FED injetou US\$ 430,25 bilhões e o Banco Central da Europa, US\$ 2,9 trilhões, perfazendo um total de US\$ 3,3 trilhões nos mercados monetários entre 27 de julho e 12 de setembro, a fim de evitar uma subida abrupta das taxas de juros de curto prazo e permitir a reorganização dos portfólios dos investidores. [...]. O Banco do Japão, por sua vez, injetou US\$ 3,3 bilhões em 16 de agosto e US\$ 6,95 bilhões em 21 de agosto. Outros bancos centrais, tais como do Canadá, da Austrália, da Noruega e de Taiwan também foram forçados a injetar liquidez em seus mercados financeiros. 
Todas estas intervenções foram importantes, mas as sucessivas declarações de perdas patrimoniais dos bancos dos Estados Unidos e da Europa aprofundaram as incertezas dos mercados e a crise instalou-se na Europa. Esta foi mais fortemente contagiada pela crise em razão das expressivas vinculações financeiras, uma vez que muitos bancos europeus possuíam grandes quantidades de papéis lastreados pelas hipotecas $s u b$ prime dos Estados Unidos.

Esta ampliação da crise gerou também uma forte queda nas principais Bolsas de Valores do mundo. No conjunto, as perdas com a desvalorização da riqueza acionária global e com a retração do crédito foram gigantescas e muitas empresas acabaram indo à falência. ${ }^{11} \mathrm{O}$ resultado final deste processo foram perdas econômicas, recessão, desemprego e endividamento dos Estados. Com isto, a crise tornou-se sistêmica e continua tendo novos desdobramentos até este momento. ${ }^{12}$

\subsection{A Nova Etapa da Crise}

Os novos desdobramentos estão vinculados ao crescente endividamento dos Estados. É que muitos deles já estavam num quadro de grande endividamento e, ao terem de injetar volumosos recursos em seus sistemas financeiros, criaram uma situação de incapacidade de pagamento de suas dívidas. Isto gerou, na prática, uma nova etapa da crise. É que o remédio aplicado trouxe como efeito colateral a piora das contas públicas e a deterioração da capacidade de pagamento dos Estados.

${ }^{11}$ É que muitas empresas, "na busca de valorização dos ganhos financeiros decorrentes de operações cada vez mais complexas, assinaram contratos de derivativos cambiais vendendo dólares em valor equivalente a anos de exportações - com a desvalorização cambial entre 2007 e 2008, contudo, os prejuízos foram tão volumosos que elas ficaram insolventes, perderam parte expressiva de seu patrimônio e tiveram que ser vendidas, incorporadas ou absorvidas" (Faria, 2011, p. 22).

${ }^{12}$ Outubro de 2011. 
Esse sinal começou a aparecer no mundo ainda no início de 2010, quando alguns países da União Europeia sinalizaram que estavam enfrentando dificuldades e que, em consequência, poderiam não dispor de recursos suficientes para pagar suas dívidas. Dentre eles encontravam-se Portugal, Irlanda, Itália, Grécia e Espanha (no início, conhecidos pelo acrônimo de PIIGS). Países mais importantes, como os EUA, surgiram nesse horizonte no início de 2011.

Assim, o novo estágio da crise passou a ser representado pelo aumento do endividamento público global (em níveis assustadores) e pelo esgotamento dos Estados na sua capacidade de recuperar a economia mundial. E esta crise fiscal dos Estados, que tem no endividamento público o seu epicentro, continua a se agravar na atualidade e deve continuar o seu caminho dos próximos anos. Um grande número de países, dentre eles os considerados ricos, ao gastarem mais do que arrecadam, geram um endividamento crescente. Em setembro de 2011, apesar de um pacote de “ajuda” superior a US\$ 100 bilhões, a Grécia continuava a pedir socorro ao FMI e à União Europeia, provocando o temor de que outros países poderiam seguir o mesmo caminho.

No continente americano, os EUA, locomotiva da economia mundial, também passaram a enfrentar enormes dificuldades nesse sentido. Afinal, a dívida pública desse país alcançou 99,5\% do PIB, tendo fechado 2010 em US\$ 13,4 trilhões. A situação é tão alarmante que os EUA dependem, para o financiamento desta dívida, não só da emissão de moeda (fato que deixa o dólar fraco na economia mundial), mas também da venda de títulos públicos mundo afora. Nesse sentido, os EUA financiam suas dívidas com as reservas dos outros países, não possuindo uma estratégia de longo prazo para a redução de seus déficits e nem um plano claro para a recuperação da economia. 
É nesse quadro que a agência de notação de risco S\&P anunciou o rebaixamento da confiabilidade de pagamento dos EUA na perspectiva de evolução da dívida pública de longo prazo deste país. Isso significa que sua capacidade de honrar os pagamentos de sua dívida está ameaçada. Por isso, é urgente uma correção de rumo, a começar pela redução do déficit orçamentário (que hoje se aproxima de $11 \%$ do PIB). Como fazer isto? Provavelmente com profundos cortes nas despesas do Estado, a iniciar pela retirada das tropas do Iraque e Afeganistão e alcançando até mesmo os programas sociais (isto é o que defendem os republicanos).

Assim, é possível afirmar que a economia dos Estados Unidos deve continuar por mais alguns anos tendo enormes dificuldades, o mesmo devendo acontecer com muitas das economias europeias. Isso significa a permanência em vigor de alguns aspectos da crise de 2007/2008.

\section{A NECESSIDADE DA CRIAÇÃO DE UM SISTEMA DE GOVERNANÇA ECONÔMICA GLOBAL}

O primeiro grande desafio da atualidade é superar este quadro de crise econômica global. O segundo é criar mecanismos que possam impedir que situações como estas voltem a acontecer. Para tanto, é fundamental a construção de um sistema de governança econômica global. ${ }^{13}$ Esta reivindicação tem sido apresentada por diversas lideranças políticas globais (preocupadas com o atual nível de descontrole e falta de transparência do sistema financeiro) e se direciona claramente para o fortalecimento das organizações econômicas multilaterais, para a colaboração entre os bancos centrais e para a adoção de medidas macroprudenciais comuns.

${ }^{13}$ Sobre a questão da governança global podem ser vistos Czempiel e Rosenau (2000); Comissão Sobre Governança Global (1996); Demos (1998) e Fundação Konrad-Adenauer (1999). 
O desafio atual é, portanto, o estabelecimento de um conjunto de regras e de procedimentos comuns que possam disciplinar e tornar mais transparentes as operações em escala global. É que cada vez mais pode ser percebido que a

dicotomia tradicional entre uma esfera doméstica ordenada e pacífica, isto é, regulada, e uma esfera interestatal anárquica e belicosa não se ajusta mais à realidade do mundo do presente [e nem garante os pressupostos necessários para o desenvolvimento sustentável das diversas regiões do planeta] (Camargo, 1999, p. 4).

Nesse sentido, é evidente que a crise econômica de 2007/2008 demonstrou o déficit de informação que as autoridades nacionais têm das eventuais implicações dos fluxos globais econômicos da atualidade e as consequências desastrosas que podem advir de um mercado planetário amplamente desregulamentado. ${ }^{14}$ Alterar esta realidade é urgente. Isso não significa a reivindicação simplista de maior presença do Estado e o fortalecimento de seus mecanismos de intervenção, ao contrário, significa apenas que deve ser reconhecido o fato de que a crise econômica de 2007/2008 revelou que o mercado global possui grandes imperfeições e que é necessário o estabelecimento de um forte sistema de governança econômica e que o mesmo seja multilateral. A saída talvez seja a criação uma agência econômica global capaz de supervisionar o funcionamento do mercado e de exercer o papel de um market maket global efetivo.

O importante é reconhecer que a crise econômica de 2007/2008 sinalizou que é necessária a adoção de "ações multilaterais coordenadas, que vão além dos tradicionais acordos de cooperação intergovernamental, e novas estruturas institucionais e regulações de alcance transnacio-

${ }^{14} \mathrm{O}$ que envolve também a ausência de informações seguras sobre "a situação de liquidez global dos bancos" (Faria, 2011, p. 22). 
nal [...]” (Faria, 2011, p. 31). ${ }^{15}$ Daí a busca de uma nova concepção de mundo que abandone a velha dicotomia intra e interEstados e que passe a pressupor que a economia da atualidade já funciona de forma interdependente e que os seus desequilíbrios somente podem ser corrigidos de forma global.

Isso significa que deve ser reconhecido que o sistema econômico atual caracteriza-se por dinâmicas e processos que obedecem a lógicas próprias, não sendo controláveis com base nas "categorias e procedimentos normativos e nos padrões espaciais e temporais construídos sob a inspiração da teoria jurídico-política clássica, [centrada no conceito de Estado e de soberania]" (Faria, 2011, p. 34). Este fato revela, de forma mais precisa, que a integração dos mercados globais tornou-os mais poderosos no processo de tomadas de decisão e, com isso, sujeitou as economias nacionais às consequências de atos e acordos decididos fora dos seus territórios.

Partindo deste fato, o presente texto reconhece que os mercados globais têm exercido um papel fundamental no mundo atual e que é necessário o estabelecimento de um sistema de governança global. Este sistema deve representar os interesses dos Estados, dos mercados e das sociedades das diversas regiões do planeta. Por isso, deve necessariamente ser multilateral e construído de forma democrática. Esta iniciativa talvez seja a única forma de garantir que os benefícios da globalização sejam minimamente socializados entre as diversas regiões do planeta e que crises econômicas, como a que se conformou em 2007/2008, sejam prevenidas e seus custos evitados.

\footnotetext{
${ }^{15}$ Isto significa que talvez não seja mais suficiente o conceito de governança global estabelecido pelo Conselho de Roma: "Conjunto de mecanismos de gestão de um sistema social e de ações definidas no sentido de garantir a segurança, a prosperidade, a coerência, a ordem e a continuidade do próprio sistema mundial” (apud Milani, 1999, p. 105).
} 


\section{CONSIDERAÇÕES FINAIS}

Diante do exposto, pode-se afirmar, mesmo sem qualquer certeza, sobre o término do impacto desta grande crise (que ainda está processando-se de forma evidente no caso dos PIIGS), que não se trata de uma mera crise conjuntural como outras que se verificaram ao longo das últimas décadas, tampouco se trata de uma crise de impactos meramente financeiros, mas sim de uma crise que abalou significativamente as estruturas econômicas da economia global; uma crise que deixa como tarefa repensar alguns dogmas que estiveram em grande evidência nas últimas décadas, em especial a pressuposição da autorregulação do mercado global.

Esta retomada ajudará a romper a atual dissociação hoje existente entre economia, política e sociedade e a resgatar "fatores como justiça social, prosperidade para todos, coesão social, igualdade, identidades culturais” (Kazancigil, 2002, p. 59). Isto é fundamental para a normalização do mundo que hoje pode ser caracterizado como um mundo em descontrole (Giddens, 2000) e para o estabelecimento de um novo modelo de desenvolvimento, que seja democraticamente construído, ecologicamente sustentado e minimamente justo na distribuição da riqueza.

O que permanece em aberto é, contudo, como construir este sistema, pois os Estados têm se mostrado reféns da estrutura financeira global existente e esta tem se posicionado de forma contrária à adoção de medidas disciplinadoras e estimulado ganhos especulativos em detrimento de ganhos produtivos. Este é, portanto, o grande desafio da atualidade e de todos aqueles que acreditam nas virtudes das mediações institucionalizadas e no futuro da humanidade. 


\section{REFERÊNCIAS}

ARTURI, Carlos; OLIVEIRA, Renato de. Introdução. In: ARTURI, Carlos; MILANI, Carlos; SOLINÍS, Germán (Org.). Democracia e governança global: que regulações para o século XXI. Porto Alegre: UFRGS, 2002.

CAGNIN, Rafael Fagundes; CINTRA, Marco Antonio. Os ciclos de ativos, crédito e investimento da economia americana após 1982. In: Novos Estudos Cebrap, n. 79, São Paulo, Cebrap, nov. 2007.

CAGNIN, Rafael Fagundes. O ciclo dos imóveis e o crescimento econômico nos Estados Unidos 2002-2008. In: São Paulo: USP, Estudos Avançados, v. 23, n. 66, 2009.

CAMARGO, Sonia de. Governança global: utopia, desafio ou armadilha? In: FUNDAÇÃO KONRAD-ADENAUER (Org.). Cadernos Pesquisas, n. 16. Governança global: reorganização da política em todos os níveis de ação. São Paulo: Konrad Adenauer-Stiftung, 1999.

COMISSÃO sobre governança global. Nossa comunidade global. Rio de Janeiro: Fundação Getulio Vargas, 1996.

CZEMPIEL, Ernst-Otto; ROSENAU, James N. (Org.). Governança sem governo: ordem e transformação na política mundial. Brasília: UNB, 2000.

DEMOS. Governar a globalização: a política da inclusão: a mudança de responsabilidade compartilhada. México: Unesco, 1998.

FARIA, José Eduardo (Org.). Direito e globalização econômica: implicações e perspectivas. São Paulo: Malheiros, 1994.

. O Estado e o Direito depois da crise. São Paulo: Saraiva, 2011.

FUNDAÇÃO Konrad-Adenauer (Org.). Cadernos Pesquisas, n. 16. Governança global: reorganização da política em todos os níveis de ação. São Paulo: Konrad Adenauer-Stiftung, 1999.

GIDDENS, Anthony. As conseqüências da modernidade. 2. ed. São Paulo: Editora Unesp, 1991. 
GIDDENS, Anthony. Mundo em descontrole: o que a globalização está fazendo de nós. Rio de Janeiro: Record, 2000.

GONTIJO, Claudio. Raizes da crise financeira dos derivativos subprime. Belo Horizonte: UFMG; Cedeplar, 2008.

GOWAN, Peter. Crise no centro: conseqüências do novo sistema de Wall Street. In: Estudos Avançados, São Paulo: USP, v. 23, n. 65, 2009.

HOLSTI, Kalevi J. Governança sem governo: a poliarquia na política internacional européia do século XIX. In: CZEMPIEL, Ernst-Otto; ROSENAU, James N. (Org.). Governança sem governo: ordem e transformação na política mundial. Brasília: UNB, 2000.

IANNI, Octavio. A sociedade global. 4. ed. Rio de Janeiro: Civilização Brasileira, 1996.

KAZANCIGIL, A. A regulação social e a governança democrática da mundialização. In: MILANI, C.; ARTURI, C.; SOLINÍS, G. (Orgs.). Democracia e governança mundial: que regulações para o século XXI? Porto Alegre: Ed. Universidade; UFRGS; Unesco, 2002.

KRUGMAN, Paul. A crise de 2008 e a economia da depressão. Rio de Janeiro: Editora Elsevier, 2009.

MATIAS, Eduardo Felipe Pérez. A humanidade e suas fronteiras: do Estado soberano à sociedade global. São Paulo: Paz e Terra, 2005.

MILANI, Carlos R. S. Governança global e meio ambiente: como compatibilizar economia, política e ecologia. In: FUNDAÇÃO KONRAD-ADENAUER (Org.). Cadernos Pesquisas, n. 16. Governança global: reorganização da política em todos os níveis de ação. São Paulo: Konrad Adenauer-Stiftung, 1999.

SANTOS, Milton. Técnica, espaço e tempo: globalização e meio técnico-científico. $3^{a}$. ed. São Paulo: Hucitec, 1997.

Recebido em: 5/10/2012

Aprovado em: 29/10/2012 